\title{
IMPACT AND IMPLICATIONS OF NONTECHNICAL SKILLS IN ANAESTHESIOLOGY
}

\author{
${ }^{1}$ Dr. Arun Kumar Gupta, ${ }^{2}$ Dr. D. S. Divekar \\ ${ }^{I}$ Assistant Professor, ${ }^{2}$ Professor, Department of Anaesthesiology \& Critical Care. Rural \\ Medical College, Loni, Maharashtra, India, 413736 \\ *Correspondence:_guptaarun71@gmail.com
}

Key words: Non technical skills, Anaesthesia, Errors, Education \& Training

Crucial role of Non technical skills (NTS) in the dynamic environment of day to day anaesthetic practice is emerging. Rather than mere acceptance, efforts are being made world over to identify and assess them to overcome their negative effects by structured taxonomy both in real time and simulated conditions. Reduction in anaesthetic accidental mishaps and near misses is the prime concern from the point of patient safety and towards that end training and education have a pivotal role.

Anaesthesiology, a challenging and demanding speciality, is neither a diagnostic nor a therapeutic speciality. Progress and advances in various surgical specialities and super specialities would have been stunted but for the advances by leaps and bounds by this relatively young supporting speciality. Anaesthesia is conducted in a highly complex environment and anesthesiologists deal with many ill structured problems in dynamic situations where many variables are operating and there are multiple team members from different professions ${ }^{1}$.

Anaesthesiology has remained in the forefront by quickly learning from the experiences of high reliability organizations like civil aviation, nuclear power industries, off shore oil explorations etc. where the safety concerns are paramount. These organizations have recognized the role of these non technical skills (NTS) by human factor research in the causation of mishaps and accidents during the last two decades or so. Health care professions have also become more aware of the importance of NTS in the delivery of a safe high quality medical care. Safety and efficiency in any field of work is not limited to possession of thorough academic knowledge and skillful application of the technical skills needed in that particular field but it also encompasses the basic human behaviour and attitude of individuals during the course of performance of their duties.
Detailed investigations of adverse health care events (an event or omission arising during clinical care and causing physical or psychological injury to a patient) and near misses (a situation where events or omissions or sequences do not worsen further either due to a compensatory action or by good fortune) have shown that in almost eighty percent of the cases the underlying cause is poor application of NTS. A key counter measure to errors and adverse events development is to improve management in the workplace by achieving consistently a high level of NTS performance ${ }^{1}$.

NTS have a vital critical role in anaesthetic practice but have not been addressed to during postgraduate training in anesthesiology and this needs to be corrected at the earliest.

\section{What are NTS?}

NTS are human behaviors which enhance safety and efficiency along side the knowledge and technical skills needed in any field of work. They are not directly related to medical expertise, drugs or equipment. Two categories of NTS have been recognized:

1. Cognitive and Mental skills which include planning, decision making, situation awareness etc.

2. Social and Interpersonal skills like coordinated team working, leadership, 
communication etc. Though the importance and significance of NTS in clinical work areas has been accepted they are not addressed to during traditional teaching. Historically it is assumed that postgraduates would acquire these skills by 'osmosis' by experience and observing their role models during the training period.

\section{ROLE \& ASSESSMENT}

Recognizing the gaps during training period, various methods have been adopted by different researchers to delineate the role of NTS in anaesthetic practice. For better appreciation, data collection could be grouped under the following headings ${ }^{2}$ :

1. Incident Reporting.

2. Observational studies in real life

3. Virtual observational studies in simulation centres.

4. Attitude Questionnaires

5. Theoretical Models.

\section{Incident Reports}

Cooper and colleagues ${ }^{3}$ while investigating the cause of preventable incidents involving human error or equipment malfunction found that eighty two percent of the incidents were due to human errors and only fourteen percent were due to equipment failure. Various factors under human errors resulting in these preventable incidents included poor communication, failure to recognize a developing problem (inattention, carelessness, haste, fatigue), failure to follow set personal routine or institutional practice, flawed decision making (distraction, insufficient preparation) and excessive dependency on other personnel.

Different groups have collected data on different formats $^{4,5}$ but their analysis is more at a operational level and does not provide a finer grained level of information necessary to understand where the skills broke down and provide only a limited insight into NTS. More advanced techniques of analysis and data collection from incident reporting system would identify the limitations in human factors and deficiency in NTS which contribute significantly to adverse outcomes.

\section{Observational Studies}

These allow human behaviour to be examined in real operating environment and in simulation centers. Real time studies provide information when things are going right as well as when things have gone wrong. Studies under simulated conditions can be repeatedly measured and compared under controlled conditions.

In real time studies observations are made either directly or by setting up a number of video cameras for analysis at a later stage. Limitations of such studies include that normal behaviour of the team is altered in the presence of the researchers, inability to directly observe the entire team all the time as well as the issues related to consent and confidentiality. Despite these limitations these studies have observed in twenty to forty percent of times that the behaviour of the different teams was unsatisfactory and was below the set standard in the area of communication and coordination affecting the decision making process as well as affecting the overall clinical performance ${ }^{2}$. Knowledge based errors as well as procedural type of errors are more frequent under stressful, emergency time pressured situations due to shortcuts, task shedding, delegation of tasks by more verbal communication and due to uncertainty ${ }^{2,6}$.

A pilot study into the NTS in operating rooms of our institution done over a period of eight months has shown similar results leading to a number of preventable errors and mishaps. Salient points observed were carelessness, haste, inattention, distraction, failure to follow set routine institutional guidelines and excessive dependence on other personnel.

Simulator studies have shown more experienced anaesthetists have better situation awareness to recognize relevant cues and take early suitable corrective action. Junior members who are trained on simulators may perform better than inexperienced trainees ${ }^{7,8}$. Skill to focus on information gathered and to integrate it with the existing knowledge to produce a solution comes with experience and training.

These observational studies show that key skills necessary for better performance are verbal 
communication, individual and team situational awareness, problem recognition, decision making and re-evaluation.

\section{Attitude Questionnaire}

Questionnaire based surveys have shown similar findings in respect of importance of communication and coordination in addition to technical proficiency but contrary to observational studies analysis of mishaps and near misses many anaesthetists felt that their performance was unaffected by stress and fatigue. Unrealistic expectation of human performance should not encourage anaesthetists to accept errors as normal occurrence but they should realize that critical incidents may occur due to stress and many non technical factors.

\section{TRAINING}

Based on a number of incident reports, simulator studies, and cognitive psychological theories and on experience of other high reliability domains like aviation, Gaba and colleagues ${ }^{9},{ }^{10}$ have developed a comprehensive cognitive model for dynamic decision making and crisis management which is used as a framework for Gaba's simulator training programme in Anaesthesia Crisis Resource Management (ACRM) course which emphasizes NTS. Aim of this course is to prevent, ameliorate and resolve critical incidents. This course is conducted over three years of postgraduate training and the scenarios become more complex as it progresses. Key points are in Table-1. In this table the first model of activity is at 'sensory motor level' wherein the anaesthetist is engaged in basic observation and verification (checking the details of the patient, checking the machine and monitors and observing the activity of other team members) giving him a good level of situation awareness. Subsequently he confirms and crosschecks the information gathered, the absence of which may contribute to unforeseen incidents occurring. Next stage is the 'procedural level' wherein from the information gathered, the Anaesthetist tries to identify and anticipate problems to formulate a course of action in respect of a particular patient on a particular day. The formulated plan of action may be on the lines of a routine activity or if the identified problem is novel the model moves to the next 'Abstract level' where in based on basic principles of medical knowledge and step by step reasoning activity a gross alteration in the plan of action is done. This alteration is used alongside of precompiled responses and is time consuming. Next step is the implementation of plan of action developed during the problem solving level. Execution of tasks like administering drugs, variation of dosages and concentration or adjusting settings on the anaesthesia machine or changing circuits gets again included in the sensory motor level of activity. If suitable corrective action and effective implementation of the alternative action is not taken errors / slips are likely to crop up. 'Supervisory cognitive level' is responsible for coordination of tasks, allocation of time and attention for problem recognition, making observation and for implementing the action plan. This level varies with the experience of the anaesthesiologist and it may be partly automatic and partly under conscious control. This important level has potential for errors/ failures unless suitable modifications are done by constant appreciation and reevaluation of the situational changes. The highest 'Resource management level 'is under conscious deliberate control, and it coordinates the activities necessary for leadership, monitoring, crosschecking, communication and interpersonal relations with all team members.

This course has been accepted world wide with great interest and in some countries it is a legal requirement. This course is run in a mock up operating theatre using high fidelity Simulator and the scenarios include reading, didactic presentation, video analysis etc. where participants are exposed to critical clinical incidents and debriefed later on their knowledge, technical skills and NTS. During debriefing it was found that the scores of the participants strongly correlated with leadership, communication and distribution of workload. It was also seen that great variability in the scores given by different assessors in respect of behavioral performance highlighting the difficulties in identifying and measuring NTS. 
Table 1: Key Points

\begin{tabular}{|l|l|l|}
\hline $\begin{array}{l}\text { Cognitive } \\
\text { Level } \\
\text { Lowest To } \\
\text { Highest }\end{array}$ & Mental Activity & Activities \\
\hline $\begin{array}{l}\text { Sensorimotor } \\
\text { level }\end{array}$ & $\begin{array}{l}\text { Processing } \\
\text { sensory data and } \\
\text { managing routine } \\
\text { tasks }\end{array}$ & $\begin{array}{l}\text { Observation, verification, } \\
\text { problem recognition and } \\
\text { assessment. routine physical } \\
\text { activities such as drug } \\
\text { administration }\end{array}$ \\
\hline $\begin{array}{l}\text { Procedural } \\
\text { level }\end{array}$ & $\begin{array}{l}\text { Solving problems } \\
\text { by applying rules }\end{array}$ & $\begin{array}{l}\text { Identify and solve problems by } \\
\text { applying precompiled responses }\end{array}$ \\
\hline Abstract level & $\begin{array}{l}\text { Solving problems } \\
\text { by reasoning }\end{array}$ & $\begin{array}{l}\text { Use mental resources to create } \\
\text { mental model of problem and to } \\
\text { work out solution from first } \\
\text { principles }\end{array}$ \\
\hline $\begin{array}{l}\text { Supervisor } \\
\text { level }\end{array}$ & $\begin{array}{l}\text { Supervisory } \\
\text { control }\end{array}$ & $\begin{array}{l}\text { Allocates attention and mental } \\
\text { resources }\end{array}$ \\
\hline $\begin{array}{l}\text { Resource } \\
\text { management } \\
\text { tool }\end{array}$ & $\begin{array}{l}\text { Resource } \\
\text { management }\end{array}$ & $\begin{array}{l}\text { Uses available resources, } \\
\text { information equipment and } \\
\text { personnel to manage } \\
\text { perioperative care of patient }\end{array}$ \\
\hline
\end{tabular}

Introduction of computer driven patient simulators has enhanced the interest in NTS with at least fifty percent of emphasis on critical resource management behaviour ${ }^{11}$. Interestingly significant number of adverse events (up to 5\%) have been reported when the participants are experts ${ }^{12}$.

Team Oriented Medical Simulation (TOMS) course with similar curriculum was developed at basal but the emphasis is on social psychology of team interactions rather than cognitive model of ACRM course. Team model proposed by Helmreich and Schefer ${ }^{13}$ is shown in Table-2. Focus of attention in the team model is the entire operating room Team rather than individual anaesthetist's mental processes. Components of the model are 'Team input factors'(organizational, team and Individual) 'Team performance factors' (interaction and task type) and 'team outcome factors'( Team and organizational) in a feed back loop.

Organizational team input factors (how a department. is organized, coordinated, what are the interpersonal relations/ communication, how the reserves are utilized) are those which are considered to produce system errors. Operating room team members have a different background (medical / surgical / paramedical, nursing, anaesthesia and so on) and have different expectations though working towards one aim. The group expectations, capabilities and ways of practice will vary and unless coordinated is likely to lead to adverse events/ slips / near misses. Here in the individual's attitude, aptitude, personality and motivation, physical fitness etc. will be a vital input for the entire team.

Team performance will be affected by interaction of team members of the same speciality / other speciality as well as by the different types tasks (Cognitive, technical, non technical tasks etc). Focus of this model is on the identification of these factors and how they are maintained rather than on descriptive details. Non technical tasks identified are forming and maintaining a leadership, communication and decision making, situation awareness, monitoring for changes needed and maintaining the load of work.

Final component of the model is multiple outcomes related to the team/individual/ organizational. Patient safety is the most important outcome which in turn has an impact on the morale and job satisfaction of team members as well as on the achievement of organizational goals. Debriefing and discussion of reported incidents aids in intervention needed to modify performance by training and safety reporting systems. Anaesthetist's performance is considered as a part of the performance of the entire surgical team and the various external factors which influence it.

Table 2: Team Model

\begin{tabular}{|c|c|c|}
\hline Inputs & $\begin{array}{l}\text { Team performance } \\
\text { function }\end{array}$ & outcome \\
\hline $\begin{array}{l}\text { Organizational } \\
\text { factors } \\
\text { Resources, } \\
\text { organization and } \\
\text { practices } \\
\text { Cultural issues, } \\
\text { Patient }\end{array}$ & $\begin{array}{l}\text { Interaction with } \\
\text { colleagues } \\
\text { Same specialty } \\
\text { Different specialty }\end{array}$ & $\begin{array}{l}\text { Team } \\
\text { Patient safety } \\
\text { Team performance }\end{array}$ \\
\hline $\begin{array}{l}\text { Team factors } \\
\text { Composition } \\
\text { Familiarity } \\
\text { Group and } \\
\text { intergroup norms }\end{array}$ & $\begin{array}{l}\text { Task type } \\
\text { Case management } \\
\text { Technical } \\
\text { Cognitive } \\
\text { Social/interpersonal }\end{array}$ & $\begin{array}{l}\text { Individual and } \\
\text { organizational } \\
\text { Attitudes } \\
\text { Job satisfaction } \\
\text { Personal developmen }\end{array}$ \\
\hline $\begin{array}{l}\text { Individual factors } \\
\text { Attitudes, personality } \\
\text { and motivation } \\
\text { Knowledge and } \\
\text { training } \\
\text { Stress and fatigue }\end{array}$ & & \\
\hline
\end{tabular}

Integration of Gaba's ACRM Cognitive model and Helm Reich's TOMS would lead to better understanding of anaesthetists performance. 
Significant points realized during the conduct of these courses are:-

a) Leadership in OT environment is ill defined

b) Several teams (nursing, anaesthesia, surgical and paramedical) with different levels of knowledge, technical and NTS are working together with ultimate goal of patient safety but with disagreement about over all priority, sequence in which they are to be tackled

c) Each patient has a unique set of problems and the impact of anaesthesia and surgery on his/her pathophysiology is not well understood ${ }^{9}$.

Information gathered from these courses led to the beginning of a project on Anaesthesiologists Non Technical Skills (ANTS) for developing a Behavioural Marker System which ultimately could be grounded into routine anaesthetic practice. Taxonomy of ANTS will provide a frame work for further development of an integrated model.

\section{TAXONOMY OF ANTS}

Though it is clear NTS play a central role in anaesthetic practice, full realization of which skills are important and how they are used in daily practice is hitherto not understood. Efforts for developing a validated Behavioural Marker System (BMS) under ANTS project has been taken up by National Health Service in UK and by other workers. Experience from industrial field and from observations made during anaesthesia both in real life and in simulator studies forms the basis of this project. It is well known that BMS is context specific and varies in different professions as well as in different cultures and within the same profession as well.

A prototype BMS was developed to investigate its experimental validity, reliability and usability by observing and rating a target of 50 trained consultants $^{14}$. Results have been encouraging.This hierarchical system has four skill categories (Task management, Team working, Situation Awareness and Decision Making) which are further divided into observable 15 elements. (Table-3)

Each element has linked observable behaviour markers of both good and bad practice (Table-4). Assessment is made at both these levels on a four point scale (Table-5) with an option for indicating the non observed skill for that particular scenario. Stress Management which is difficult to observe and communication which is the means for inferring other skills have not been separately identified in this system.

The ANTS project was the first empirically derived and validated investigation of NTS required for the health profession. Resulting taxonomy can form the basis for hospital based teaching and simulated teaching despite its limitations which can be overcome as experience is gained.

\section{Table 3: The ANTS system}

\begin{tabular}{|l|l|}
\hline Category & Element \\
\hline Task management & Planning and preparing \\
& Prioritizing \\
& Providing and maintaining standards \\
& Identifying and utilizing resources \\
\hline Team working & Co-coordinating activities with team \\
& members \\
& Exchanging information \\
& Using authority and assertiveness \\
& Assessing capabilities \\
& Supporting others \\
\hline Situation awareness & Gathering information \\
& Recognizing and understanding \\
& Anticipating \\
\hline Decision making & Identifying options \\
& Balancing risks and selecting options \\
& Re-evaluating \\
\hline
\end{tabular}

Table 4: Example of behavioral markers for the element: co-coordinating activities with team members

\begin{tabular}{|l|l|}
\hline $\begin{array}{l}\text { Behavioral markers for } \\
\text { good practice }\end{array}$ & $\begin{array}{l}\text { Behavioral markers for poor } \\
\text { practice }\end{array}$ \\
\hline $\begin{array}{l}\text { Confirms roles and } \\
\text { responsibilities of } \\
\text { team members }\end{array}$ & $\begin{array}{l}\text { Does not co-ordinate with surgeons } \\
\text { and other groups }\end{array}$ \\
\hline $\begin{array}{l}\text { Discusses care with } \\
\text { surgeons or Colleagues }\end{array}$ & $\begin{array}{l}\text { Relies too much on familiarity of team } \\
\text { for getting things done }\end{array}$ \\
\hline $\begin{array}{l}\text { Considers requirements of } \\
\text { others before acting }\end{array}$ & $\begin{array}{l}\text { Intervenes without informing/involving } \\
\text { others }\end{array}$ \\
\hline $\begin{array}{l}\text { Co-operates with others to } \\
\text { achieve Goals }\end{array}$ & Does not involve team in tasks \\
\hline
\end{tabular}

Table 5: ANTS system rating options

\begin{tabular}{|l|l|}
\hline Rating label & Description \\
\hline $4=$ good & $\begin{array}{l}\text { Performance was of a consistently high standard, } \\
\text { enhancing patient safety; it could be used as a } \\
\text { positive example for others }\end{array}$ \\
\hline $3=$ acceptable & $\begin{array}{l}\text { Performance was of a satisfactory standard but } \\
\text { could be improved }\end{array}$ \\
\hline $2=$ marginal & $\begin{array}{l}\text { Performance indicated cause for concern, } \\
\text { considerable improvement is needed }\end{array}$ \\
\hline $1=$ poor & $\begin{array}{l}\text { Performance endangered or potentially } \\
\text { endangered patient safety, } \\
\text { serious remediation is required }\end{array}$ \\
\hline not observed & Skill could not be observed in this scenario \\
\hline
\end{tabular}


Training and assessment of performance in clinical anaesthesiology is controversial and has seen many changes with the experience gained at different stages. Whatever the methodology adopted it is essential not to divert from the primary aim of improving clinical performance, by preventing and managing adverse clinical events.

ANTS system has been widely accepted and is accessible on net : www.abdn.ac.uk/iprc/ANTS. Yee and colleagues ${ }^{15}$ have confirmed performance of trainees improves with repeated training. Integration of NTS training with or without the ANTS system is still at an early stage and lot more needs to be done.

Following the lines of ANTS system a prototype BMS of NTS for Surgeons (NOTSS) has been developed and is under investigation. Similarly research into the role of human factors and NTS in Intensive care Unit is underway ${ }^{16}$. Obstetrics, Acute General Medicine and Emergency Medicine have also shown interest and would not like to lag behind in the training of their postgraduates.

\section{Conclusions}

Good performance in Non technical skills is important in the reduction of errors and also in mitigating the effects of these errors in the areas where SAFETY is of paramount concern. ANTS' development has been very significant in the last decade or so. Explicit developments in Simulator centre training have been made but much more is in the offing before being embedded into Anaesthesiology training curriculum. Training material and trainers are to be developed and prepared. Integrated programmes for the entire surgical team offers exciting opportunity of team training with targeted feedback for individual members as NTS is evolving for various surgical disciplines.

Future generation of anaesthesiologists have to horn in not only fast changing advances in the knowledge of anaesthesia but also sharpen their technical skills to fully exploit the advances in the technological field. They need to armour themselves with evolving changes be it in the academic field or in the arena of NTS which hitherto have been given only a passing glance, to ensure their survival and success in the scenario of tremendous challenges which they will have to face.

\section{References}

1. Cashman JN, Grounds RM. 2008:Non technical skills in Anaesthesia, In: Rona Patey, Recent Advances in Anaesthesia, 24th Eds.:197-212.

2. Fletcher GCL, et al. The role of non technical skills in anaesthesia: A review of Current Literature, Br. J. Anaesth 2002; 88(3): 418-29.

3. Cooper JB, et al. Preventable Anaesthesia Mishaps: a study of human factors. Anaesthesiology 1978; 49: 399-406.

4. Runciman WB, et al. Errors, incidents \& accidents in anaesthesia practice. Anaesth Intens Care 1993; 21: 506-19.

5. Williamson JA, et al. Human Failure: analysis of 2000 incident reports. Anaesth Intens Care 1993; 21: 678-83.

6. Mackenzie CF, et al. An audio video system for automated data acquisition in clinical environment. J Clin Monit 1995; 11: 335-41.

7. Gaba DM, et al Production pressure in work environment. Anaesthesiology 1994; 81: 488500 .

8. Greaves JD, et al. Watching anaesthetists' work. Br J Anaesth 2000; 84: 525-533.

9. Rall M, Gaba DM. Patient Simulators.in Miller's Anaesthesia, 6 th edn. Philadelphia, PA: Churchill Livingstone, 2005; 3073-103.

10. Forrest JB, et al. Multi centre study of general anaesthesia. Anaesthesiology 1990; 72; 262268.

11. Gaba DM, DeAnda A. The response of anaesthesia trainees to simulated critical conditions. Anaesth Analg 1989; 68:444-451.

12. Gaba DM, et al. Assessment of clinical performance during simulated crises using both technical \& behavioural ratings. Anaesthesiology 1998; 89: 123-147.

13. Helmreich RL, et al.Human factors in the operating room: safety, efficiency \& morale. Clin anaesthesiol 1996; 10: 277-295.

14. Fletcher G, et al. ANTS: Evaluation of a Behavioral Marker System. Br J Anaesth 2003; 90: 580-588.

15. Yee $b$ et al. NTS in anaesthesia crises management with respect exposure to simulation based education. Anaesthesiology 2005; 103:241-248.

16. Reader R, Flin R, et al. NTS in intensive care unit. Br J Anaesth 2006; 96:551-519. 